\section{How do Service Quality, Value, Pleasure, and Satisfaction Create Loyalty to Smart Dockless Bike-Sharing Systems?}

\author{
Yong Liu ${ }^{1}$ \\ Danyu Huang ${ }^{1}$ \\ Meng Wang ${ }^{1}$ \\ Yaru Wang ${ }^{1}$ \\ ${ }^{1}$ Chengdu University of Technology, College of \\ Management Science, Chengdu, China
}

Recebimento:

08/12/2018

Aprovaçáo:

03/15/2019

Editor responsável:

Prof. Dr. Francisco José Liébana

Avaliado pelo sistema:

Double Blind Review

\begin{abstract}
Purpose - The purpose of this research is to investigate which factors influence users' loyalty to smart dockless bike-sharing systems (DBSS).
\end{abstract}

Design/methodology/approach - A sample of 374 subjects who had previously experienced smart DBSS was obtained and the partial least squares (PLS) method was performed to analyze the measurement and structural models.

Findings - The results indicated that customer loyalty was the final construct produced by perceived green value, customer satisfaction, and perceived pleasure, which were found to be partial mediators between service quality and customer loyalty.

Originality/value - This study (1) provides a new perspective from which to examine consumer loyalty behavior in a smart DBSS context, (2) it identifies the role of service quality as an important stimulus, (3) it confirms that perceived pleasure not only has an effect on customer loyalty, but also acts as an excellent mediator, and (4) it provides empirical evidence for smart DBSS providers to enhance the adoption of green transport and to strengthen customer loyalty to smart DBSS.

Keywords - Bike-sharing systems; Service quality; Satisfaction; Loyalty

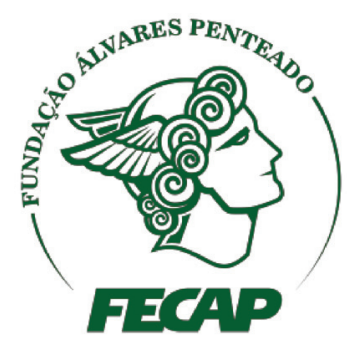

Revista Brasileira de Gestáo de Negócios

DOI:10.7819/rbgn.v22i3.4070 


\section{Introduction}

Under pressure from rapid urbanization and motorization, the urban environment has been deteriorating in China (Tang, Pan, \& Fei, 2017) and urban transport plays a principal role in air pollution (International Energy Agency - IEA, 2016). Thus, many modes of green transport, such as bikes, urban rail transit, and electric vehicles, have been proposed to reduce the impacts of conventional urban traffic on the environment (Fishman, Washington, \& Haworth, 2012; Zhang, Thomas, Brussel, \& Maarseveen, 2017). Of these various forms of green transportation, bike-sharing systems (BSS), which provide self-service and short-distance bike rental services for multi-target people in public places, are considered the most effective form of green transportation (Optimising Bike Sharing in European Cities - OBIS, 2011; Zhang et al., 2017). Thus, there has been rapid development of bike-sharing programs throughout Asia, Europe, and the US in recent years (Shaheen, Guzman, \& Zhang, 2010). However, the use of these traditional BSS is still not high for various reasons, such as inconvenient locations, imbalanced capacity of bike stations, damage, and theft (Chen, 2016a; Fishman, Washington, Haworth, \& Watson, 2014).

Dockless bike-sharing systems (DBSSs), a smart bike-sharing system integrating advantages of the sharing economy, the internet of things, and bicycle manufacturing (iResearch, 2017), have been springing up across China since June of 2015. Compared with traditional BBS, smart DBSS integrate mobile payment and global positioning system (GPS) tracking, which greatly increases the ease of use and management of DBSS. A user can easily locate a bike and unlock it by scanning its quick response (QR) code via a smartphone app. The bikes can be parked anywhere that allows bike parking. The scale of supply is also not limited by the capacity of the docking station. As a new green traffic mode and commerce mode, smart DBSS have attracted investors and entrepreneurs and have experienced massive growth in numbers in many Chinese cities (ResearchInChina, 2017). Since the second half of 2016, at least 30 firms with more than two million bikes have been involved in this industry (ResearchInChina, 2017). However, the usage rates of smart DBSS are well below the companies' expectations. By the end of 2017, six companies had gone bankrupt because they had not obtained and maintained enough users (YIN, 2017). Thus, it is currently an interesting issue for researchers and practitioners to attempt to understand the factors influencing BSS usage.

Numerous studies have examined the factors associated with bike sharing. Most of the literature focuses on the impact of situational factors on BSS, such as bike fleet size, surrounding built environment, bicycle infrastructure, and weather conditions (Bordagaray, Dell'Olio, Fonzone, \& Ibeas, 2016; Shaheen, Zhang, Martin, \& Guzman, 2011; Zhao, Deng, \& Song, 2014). Some researchers have investigated the effect of demographic factors on BSS, such as gender, age, occupation, and income (Fishman, Washington, Haworth, \& Watson, 2015; Guo, Zhou, Wu, \& Li, 2017; Winters, Sims-Gould, Franke, \& McKay, 2015). Also, several studies have focused on the impact of psychological factors on BSS, such as perceived green value, subjective norms, and environmental trust (Hazen, Overstreet, \& Wang, 2015; Chen, 2017; Chen \& Lu, 2016). Although these studies have provided useful insights on the sustainable development of traditional BSS, it is unclear whether these factors have the same effect on smart DBSS. It is necessary, therefore, to restudy the factors associated with the latter. In addition, the existing literature focuses mainly on the impact of situational factors on smart DBSS (Shen, Zhang, \& Zhao, 2018). Some scholars believe that it is very important to study users' initial intention and continuance intention to use a given transportation tool from the psychological perspective (Chen, 2016a, 2017; Chen \& Lu, 2016; Kaplan, Manca, Nielsen, \& Prato, 2015). According to iiMedia (2017), the number of users 
of smart DBSS in China reached 209 million in 2017. Thus, it is critical to understand the factors that affect these users' continued usage intentions in the context of smart DBSS.

From the users' perspective, smart DBSS is a novel mode of transportation service, providing bicycle rental and related services, and users' acceptance and sustained use of smart DBSS will determine the future of this traffic model. Some researchers have argued that customer loyalty is a vital predictor of users' sustained behaviors relating to a particular product or service (Khatibi, Ismail, \& Thyagarajan, 2002; Kotler \& Singh, 1981). Although Chen (2016a, 2016b) confirmed that perceived pleasure and perceived green value can motivate green loyalty in the Taiwanese public bike-sharing context, what factors trigger perceptive values and perceived pleasure remains unclear. According to the theory of qualitysatisfaction-loyalty (QSL), service quality is a crucial factor strongly affecting satisfaction, which, in turn, stimulates customer loyalty (Anderson \& Fornell, 2000; Chou \& Kim, 2009). Investigating the impact of perceived quality on public BSS adoption intention, Hazen et al. (2015) contextualized the perceived usefulness construct as perceived quality, which is only one part of service quality. Thus, the role of service quality needs further investigation in the smart DBSS context. According to studies by Chou and Lu (2009) and Oliver (2010), customer satisfaction and value are two of the most effective factors used to create customer loyalty through excellent services and quality products. However, the factors triggering perceived pleasure and perceived green value, and the mechanisms that function among service quality, perceived green value, customer satisfaction, perceived pleasure, and loyalty, remain unclear in the new generation of bike sharing. Although Kuo, Wu, and Deng (2009) and Chou and Lu (2009) verified the intermediary role of perceived value and customer satisfaction between service quality and user behavior intention, the intermediary role of perceived pleasure remains unclear. Thus, this study aims to fill this important research gap and propose a comprehensive research model in order to understand customer loyalty to smart DBSS.

This study makes some significant contributions to enriching the existing literature. First, it provides a new perspective with which to examine consumer loyalty behavior in a smart DBSS context. Second, this study identifies the role of service quality as an important stimulus which can motivate perceived green value, customer satisfaction, and perceived pleasure. Third, the study confirms that perceived pleasure not only has an effect on customer loyalty, but also acts as an excellent mediator which can pass the effect of service quality on to customer loyalty. Fourth, our research provides empirical evidence for smart DBSS providers to promote the adoption of green transport and to strengthen customer loyalty to smart DBSS.

The remainder of this article is arranged as follows. First, the theoretical background regarding smart DBSS user behavior is presented. Second, our research model and hypotheses are proposed. Next, the research methodology and the results are presented. Finally, we discuss the implications of the findings and suggest directions for future research.

\section{Theoretical Background and Hypotheses Development}

\section{I Smart DBSS and continuance intention}

The first generation of bike-sharing programs, namely the "white bike," emerged in Amsterdam in 1965, and so the history of bike-sharing programs spans more than half a century (Shaheen et al., 2010). White bikes were unlocked, free-of-charge, and for public use. However, they survived for only a short time due to a series of problems, such as theft and vandalism. Overcoming the shortcomings of the first generation of BSS, the second generation of BSS was proposed, which included the introduction of docking stations for locking, 
payment, renting, and return of the bikes. However, because there was no time limit on bike use and anonymous cash payment, the bicycle theft problem was still not completely solved. Thus, the second generation of BSS also quickly failed. With the rapid development of information technology (IT), the third generation of BSS emerged a few years later. These BSS used cashless payment, real-name registration, and dynamic pricing schemes via new applications of IT, which overcame the disadvantages of the two previous generations of BSS (Shen et al., 2018). Thus, the third generation of BSS has experienced dramatic growth and development throughout Asia, Europe, and the US (Shaheen et al., 2010). Currently, more than 600 public bicycle programs are successfully running across the world, of which approximately 162 are in China (Institute for Transportation \& Development Policy - ITDP, 2015). However, the usage of these systems is still not high for various reasons, such as inconvenient locations, imbalanced capacity of bike stations, damage, and theft (Chen, 2016a; Fishman et al., 2014).

In 2015, integrating the advantages of the sharing economy, the internet of thing, and bicycle manufacturing, smart DBSS (fourth generation BSS) were born in China. Compared to traditional bike-sharing programs, smart DBSS integrate mobile payment and GPS tracking, which greatly increases their ease of use and management. Bikes report their locations to the central server through an embedded GPS sensor and communication module. A user can easily locate a potential bike through the mobile app. After finding a bike, the user can unlock the bike by scanning the $\mathrm{QR}$ code and then ride. The bikes can be parked anywhere that allows bike parking. Smart DBSS are mostly deployed in places around major commercial hubs, subway stations, and campuses to solve the "last mile" problem. As a new green traffic mode and business opportunity, smart DBSS have attracted users, investors, and entrepreneurs. These fully "dockless" bike-sharing programs have experienced massive growth in many Chinese cities since 2016 and have since spread to other countries, such as Singapore, the UK, and the US. No less than 30 operators have taken part in this industry since the second half of 2016, with the largest operator being Mobike. Mobike took the lead by entering more than 35 domestic cities and Singapore. By the end of March 2017, Mobike held a 20\% market share with approximately 800,000 bicycles (ResearchInChina, 2017). However, the usage rates of smart DBSS have fallen far short of many companies' expectations. By the end of 2017, six companies had gone bankrupt because they had not obtained and maintained enough users (YIN, 2017). Thus, it is very important to study the influencing factors related to BSS usage.

In terms of traditional BSS, researchers have identified numerous factors influencing bikesharing usage levels. Some studies have argued that bike-sharing usage is strongly correlated with station attributes and accessibility, cycling infrastructure, and land use characteristics (Shaheen et al., 2011; Zhang et al., 2017). Also, most users' cycling behavior depends on the free ride time of public BSS (Mateo-Babiano, Bean, Corcoran, \& Pojani, 2016). Some scholars found that bike-sharing usage is significantly determined by trip distance, temperature, precipitation, and air quality (Campbell, Cherry, Ryerson, \& Yang, 2016). Several studies have deemed that a burdensome sign-up process and mandatory helmet legislation lessen the spontaneity of cycling (Fishman et al., 2012; Fishman et al., 2015). According to Sun, Mobasheri, Hu, and Wang (2017), traffic accidents and congestion, public transit accessibility, and violent crime would have an impact on the usage of BSS. Chen and $\mathrm{Lu}$ (2016) argued that users' intentions to use bike sharing is strongly correlated with perceived usefulness, perceived ease of use, and attitude. Chen (2017) found that the environment-friendly use intentions of bike-sharing services can be created by one's own perceived environmental values, environmental subjective norms, and environmental trust. Kaplan et al. (2015) deemed 
that users' intentions to use bike sharing for holiday cycling is significantly determined by favorable attitudes, interest in bicycle technology, subjective norms toward cycling, and perceived ease of cycling. Fernández-Heredia et al. (2014) believe that users' intentions to use bikes are strongly correlated with convenience, a pro-bike attitude, physical determinants, and exogenous restrictions. Benjamin et al. (2015) argued that one's intention to adopt bike-sharing programs is significantly impacted by perceived quality, perceived convenience, and perceived value. Chen (2016a) deemed that users' loyalty to public bikes can be motivated by perceived green value, perceived pleasure, perceived green usefulness, perceived behavioral control, subjective norms, and perceived ease of use. In addition, some studies have found that bike-sharing usage is strongly correlated with gender, age, education, occupation, and income (Fishman et al., 2015; Guo et al., 2017; Winters et al., 2015).

Although these studies have provided useful insights on the sustainable development of traditional BSS, it is unclear whether these factors have the same effect on smart DBSS. Thus, it is necessary to restudy the factors associated with smart DBSS. To the best of the author's knowledge, there is relatively little literature on this aspect. Although Shen et al. (2018) and Shi, Si, Wu, Su, and Lan (2018) explored the impact of situational factors and stakeholderassociated factors on bicycle usage in the context of smart DBSS, little attention has been paid to the psychological variables. Some scholars have argued that it is very important to study users' initial intention and continuance intention to use a given transportation tool from the psychological perspective (Chen, 2016a, 2017; Chen \& Lu, 2016; Kaplan et al., 2015). The initial intention is regarded as the possibility of users being willing to adopt a transportation tool initially. Continuance intention refers to the extent that a user is willing to reuse a transportation tool or recommend it to other users. According to iiMedia (2017), the number of users of smart DBSS in China reached 209 million in 2017. How to retain these users and keep them using smart DBSS is a top concern for researchers and practitioners. Thus, this study aims to fill this important research gap and to empirically explore users' sustained behaviors regarding smart DBSS based on users' psychology. Some prior studies have shown that customer loyalty is a vital predictor of users' sustained behaviors relating to a particular product or service (Khatibi et al., 2002; Kotler $\&$ Singh, 1981). Customer loyalty is regarded as the degree to which the customer commits to re-buying or re-patronizing a favorite product or service consistently into the future. Oliver (2010) and Chou et al. (2014) employed customer loyalty to examine the sustained usage behavior of users of high speed rail services. Chen et al. (2016b) examined green loyalty to investigate the sustained usage behavior of users of bike sharing in Taiwan. Thus, customer loyalty will be selected in this study to investigate the sustained usage behavior of users of smart DBSS. In this context, customer loyalty is defined as the re-usage intention or the extent to which smart DBSS are recommended to other users (Chen, 2016b).

\subsection{Service quality}

Grönroos (1984, 1988, 1990), a forerunner of research on service quality proposed and developed the model of service quality with two distinctive service dimensions: technical quality and functional quality. He defined technical quality as how the quality of service will be perceived by customers and functional quality as how the service production and delivery process are perceived (Grönroos, 1984). Subsequently, Parasuraman, Zeithaml, and Berry (1988) proposed the SERVQUAL model to estimate service quality on a multidimensional scale. They employed 22 items that estimate service quality in connection with five components: tangibles, reliability, responsiveness, assurance, and empathy. The results of SERVQUAL can be employed to examine which factors of the company's 
service are especially good or not by examining the gap between customers' expectations and performance. Although SERVQUAL has been widely employed to measure the service quality of firms in various service industries, its disconfirmation approach has been keenly contested (Izogo \& Ogba, 2015; Lien, Cao, \& Zhou, 2017). To improve on the weaknesses of SERVQUAL, Cronin and Taylor (1992) proposed the SERVPERF model to estimate service quality with the five dimensions of SERVQUAL. Unlike SERVQUAL, they argued that service quality should be customers' attitude toward the service and that using performance scores alone can achieve better reliability and validity than using different scores (Caro \& García, 2008). Jain and Gupta (2004) also believe that the SERVQUAL scale would be able to estimate greater variance in the overall quality of service with a single-item scale. SERVPERF has been widely employed to examine the key role of service quality in a large number of service industries (Lien et al., 2017). Our research aims to examine consumers' perception of service performance rather than using the expectations gap score approach; thus, SERVPERF is appropriate for use in this study for estimating the service quality of smart DBSS using the five components of tangibles, reliability, responsiveness, assurance, and empathy.

In this study, service quality is defined as a user's judgment of the overall excellence or superiority of the service of a smart DBSS firm (Parasuraman et al., 1988). Several scholars have evaluated links between service quality and satisfaction in the service industry (An \& Noh, 2009; Kaura \& Datta, 2012; Lai, 2004; Lai \& Chen, 2011). Examining the determinants of satisfaction in a short message service, Lai (2004) confirmed that service quality has a significant effect on users' satisfaction. An and Noh (2009) found that service quality positively affects customer satisfaction regarding the in-flight service of airlines. Investigating the behavioral intentions of public transit passengers, Lai and Chen (2011) argued that service quality positively influences users' satisfaction. Mugion, Toni, Raharjo, Pietro, and Sebathu (2017) also confirmed that public transport service quality has an influence on overall satisfaction in Rome. Therefore, these results indicate that consumers will be satisfied with the services of smart DBSS firms if they perceive such services as being of high quality. Customers who are satisfied are likely to become more attracted to smart DBSS firms' offerings than those who are dissatisfied. Additionally, Kuo et al. (2009), Lai and Chen (2011), and Lai, Griffin, and Babin (2009) confirmed that service quality has an important effect on perceived value. That is to say, when users perceive the service of smart DBSS firms as being of a high quality, they will understand the value of smart DBSS as a green transportation method. Similarly, investigating intentions to adopt bike-sharing programs in Beijing, Hazen et al. (2015) confirmed that perceived quality is positively associated with perceived value. Moreover, investigating users' behavior in themed restaurants, Kim et al. (2009) found that users' perceived service quality has an important impact on the level of pleasure experienced by consumers. This result implies that excellent service quality, such as an appealing bike, personalized service, reliability, responsiveness, and assurance, will increase the pleasure of users while they are riding. Therefore, we propose the following hypotheses:

H1: Service quality positively affects perceived green value.

H2: Service quality positively affects satisfaction.

H3: Service quality positively affects perceived pleasure.

\subsection{Perceived green value}

Several definitions of perceived value have been proposed by researchers based on the perspectives of money, quality, benefit, and social psychology (Kuo et al., 2009). Bishop (1984) 
argued that the monetary perspective value is generated when less is paid (such as by using coupons or promotions) for goods. Moreover, he pointed out that the quality perspective value is the difference between the money paid for a certain product and the quality of the product. Zeithaml (1988) noted that the benefit perspective value is users' overall evaluation of the utility of perceived benefits and perceived sacrifices. Sheth, Newman, and Gross (1991) also argued that the social psychology perspective value lies in the meaning of purchasing certain goods/services to the buyer's community, which carry particular meanings (such as environmental value). The connotation of perceived green value in this study is consistent with the social psychology perspective value. Thus, in the field of smart DBSS, perceived green value can be defined as a set of attributes associated with the environmental consciousness value of smart DBSS, which could generate positive word-of-mouth and motivate reuse intentions (Chen, 2016b).

Previous literature has suggested that perceived value is a vital predictor of customer satisfaction and loyalty in the service industry (Chen, 2016a; Kuo et al., 2009; Lai et al., 2009; Lai \& Chen, 2011). Kuo et al. (2009) argued that perceived value positively influences both user satisfaction and re-buy intention in the field of mobile value-added services. Lai and Chen (2011) deemed that perceived value positively affects both the overall satisfaction and behavioral intentions of public transit passengers. Additionally, Lai et al. (2009) argued that perceived value has an important effect on both user satisfaction and loyalty in the Chinese communication service industry. Also, Sumaedi et al. (2016) contended that perceived value positively influences public transport passengers' satisfaction. Benjamin et al. (2015) found that perceived value predicted $50.5 \%$ of the variance in the intention to adopt bike-sharing programs in Beijing. Chen (2017) found that users' perceived environmental value is positively associated with their environmentfriendly use intentions for bike sharing. According to Wang et al. (2018), perceived value has an impact on consumer adoption intentions for public BSS. Chen (2016a, 2016b) also argued that perceived green value has an important effect on user green loyalty to public bike use in Taiwan. These results therefore indicate that the more users feel the green value of smart DBSS, the more satisfaction and customer loyalty they will have in regard to smart DBSS and vice versa. Therefore, we propose the following hypotheses:

H4: Perceived green value positively affects satisfaction.

H5: Perceived green value positively affects customer loyalty.

\subsection{Perceived pleasure}

Existing research literature indicates that customers' emotional response has been an important factor in the service industry (Hyun \& Kang, 2014; Rezvani, Jansson, \& Bodin, 2015). Russell (1979) established the pleasurearousal (PA) model and claimed that emotions consist of two independent dimensions: pleasure and arousal, which can adequately capture the emotional responses to a stimulus. Pleasure is described as the extent to which an individual feels good, happy, or satisfied in a situation, while arousal is defined as the extent to which an individual feels stimulated, awake, or excited in a situation (Russell, 1979). Previous studies have shown that large percentages of revisiting patrons are generally those who have had positive emotional responses (e.g., pleasure) during previous visits (Hyun \& Kang, 2014; Kim \& Moon, 2009). A person who feels a higher level of pleasure in activities is more likely to frequently attend the corresponding activities (Gohm \& Clore, 2000). Thus, the perceived pleasure factor is appropriate in our study for examining users' behavior related to smart DBSS. In the context of smart DBSS, users' perceived pleasure can be defined as the extent to which an individual feels good, happy, or satisfied with the smart DBSS in use (Russell, 1979). 
Previous studies have determined that perceived pleasure is an important antecedent of user satisfaction and loyalty in the service industry (Bigné, Andreu, \& Gnoth, 2005; Chen, 2016a; Das, 2013; Kim \& Moon, 2009). Das (2013) argued that pleasure positively affects both satisfaction and word-of-mouth in the Indian banking sector. Also, Bigné et al. (2005) deemed that the pleasure dimension positively influences both visitor satisfaction and visitors' loyalty behavior in a theme park environment. In addition, Kim and Moon (2009) deemed that consumers' pleasure-feeling emotion positively influences revisit intention in the themed restaurant industry. Chen (2016a, 2016b) believes that perceived pleasure positively affects user green loyalty to public use bikes in Taiwan. These results imply that the higher the level of pleasure users feel when experiencing smart DBSS, the more satisfaction and customer loyalty they exhibit to smart DBSS and vice versa. Therefore, we propose the following hypotheses:

H6: Perceived pleasure positively affects satisfaction.

H7: Perceived pleasure positively affects customer loyalty.

\subsection{Satisfaction}

In marketing research customer satisfaction is an important latent construct. Many researchers have defined and studied customer satisfaction from different perspectives (Kotler, Philip, Keller, \& Lane, 2006; Oliver, 1980, 1981; Van Der Wiele, Boselie, \& Hesselink, 2002). However, among these definitions of user satisfaction, the expectancy-disconfirmation theory is widely employed to explain user satisfaction as a construct that represents a user's favorable/ unfavorable feelings resulting from his/her appraisal of the discrepancy between the overall performance of the goods/services producer and his/her expectation (Chou, Min, Chang, \& Lin, 2010; Kotler et al., 2006; Sumaedi et al., 2016). It indicates that satisfaction depends on the comparison of perceived performance to expectation. If the performance matches or exceeds the user's expectation, the user will be satisfied and vice versa. Thus, in the context of smart DBSS, user satisfaction can be defined as a user's favorable/unfavorable feeling resulting from his/her appraisal of the discrepancy between the overall performance of smart DBSS and his/ her expectation (Sumaedi et al., 2016). There are two different conceptualizations of customer satisfaction: transaction-specific satisfaction (which is linked to the evaluation of a particular service encounter) and cumulative satisfaction (associated with the overall evaluation of the service provider to date) (Johnson, Anderson, \& Fornell, 1995). Parasuraman et al. (1988) noted that cumulative satisfaction is more capable of examining the service performance of companies and more effective in predicting users' re-buy behaviors. Harris and Goode (2004) argued that the satisfaction construct is conceptualized as cumulative satisfaction, rather than transactionspecific satisfaction in loyalty research. Thus, cumulative satisfaction instead of transactionspecific satisfaction is appropriate in this research for examining the overall satisfaction felt toward smart DBSS.

Previous research literature has indicated that there is a significant relationship between consumer satisfaction and customer loyalty in the public transport context (Chou \& Kim, 2009; Chou et al., 2014; Han, Meng, \& Kim, 2017; Mugion, et al. 2017). Chou and Kim (2009) and Chou et al. (2014) argued that customer satisfaction positively affects customer loyalty to high speed rail in Taiwan and Korea. Mugion et al. (2017) also confirmed that overall satisfaction has an impact on users' intention to more frequently use public transport in Rome. Han et al. (2017) found that satisfaction significantly affects users' loyalty in the context of bike travel. It follows from this that higher user satisfaction leads to higher re-buy intention, and a user who is satisfied with smart DBSS is likely to patronize these services 
again and recommend them to other users. Therefore, we propose the following hypothesis:

H8: Satisfaction positively affects customer loyalty.

In addition, some researchers have argued that bike-sharing usage is correlated with demographic factors, such as gender, age, occupation, and income (Although et al., 2015; Fishman et al., 2015; Guo et al., 2017; Wang et al., 2018). It would be interesting to include some demographic factors as control variables in our proposed research framework. We hypothesize that gender, age, education, and income will lead to different degrees of loyalty to smart DBSS.

Figure 1 depicts the research model conceived for this case. It shows that service quality determines perceived green value, perceived pleasure, and customer satisfaction. Customer loyalty is affected by perceived green value, perceived pleasure, and customer satisfaction. And customer satisfaction is also influenced by perceived green value and perceived pleasure. In addition, the control variables gender, age, education, and income have different impacts on loyalty to smart DBSS.

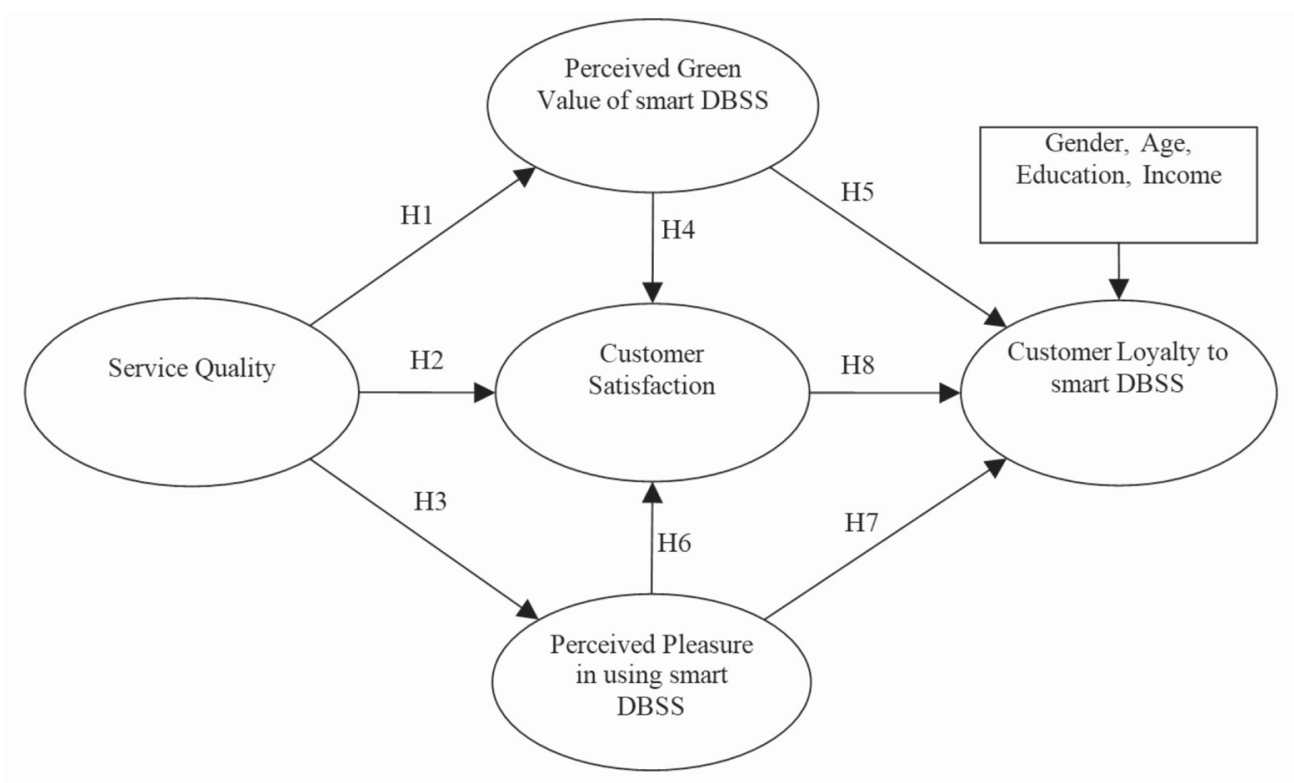

Figure 1. Research model

\section{Research methods}

\section{I Construct measurement}

The research model consists of five factors (Fig. 1). Each factor was measured with multiple items, where each item was gauged on a five-point Likert scale ranging from $1=$ "strongly disagree" to $5=$ "strongly agree." The questionnaire items in this survey instrument were based on existing literature to strengthen the reliability and validity of the research (Straub, Boudreau, \& Gefen, 2004). All items of the survey were originally developed in English. As this research was performed in China, all construct items were first translated into Chinese by two native Chinese Ph.D. students who are fluent in English, following the translation committee approach (Van de Vijver \& Leung, 1997). The initial Chinese questionnaire was pilot tested among our peers and friends. A total of 35 useful 
surveys were returned, and, according to the respondents' comments, some items were revised to enhance the clarity and understandability of the instrument. The final version survey items are described below.

\section{I.I Items of service quality of smart DBSS}

Service quality (SQ) was measured with the following five items (An \& Noh, 2009; Parasuraman et al, 1988): (SQ1) I think that smart DBSS bikes are visually appealing; (SQ2) I think that smart DBSS firms are dependable; (SQ3) I think that smart DBSS firms provide a prompt service; (SQ4) I think that the online customer service staff of smart DBSS firms can be trusted; and (SQ5) I think that smart DBSS firms provide a personalized service.

\section{I. 2 Items of perceived green value of smart DBSS}

Perceived green value (PGV) was measured using four items (Chen, 2016b): (PGV1) I think that smart DBSS environmental functions have much value for me; (PGV2) I think that smart DBSS environmental performance corresponds to my expectations; (PGV3) I think that smart DBSS have a greater environmental concern than other forms of transportation; and (PGV4) I think that I use smart DBSS because it is environmentfriendly.

\section{I.3 Items of perceived pleasure in using smart DBSS}

Perceived pleasure (PP) was assessed with the following three items (Chen, 2016b): (PP1) I think that the experience of using smart DBSS is interesting; (PP2) I think that riding smart DBSS relaxes me; and (PP3) I think that using smart DBSS makes me temporarily forget my troubles.

\section{I.4 Items of customer satisfaction in using smart DBSS}

Customer satisfaction (CS) was measured with the following three items (Chou et al., 2014):
(CS1) I think that I did the right thing when I decided to use smart DBSS; (CS2) My decision to use smart DBSS was a wise one; and (CS3) Overall, I was satisfied with the smart DBSS.

\section{I.5 Items of customer loyalty to smart DBSS}

Customer loyalty (CL) was assessed with the following three items (Chen, 2016b): (CL1) I will recommend smart DBSS to other users; (CL2) I prefer using smart DBSS to other shortdistance transportation; and (CL3) I will continue to utilize smart DBSS.

\subsection{Data collection and sampling technique}

The purpose of this study is to investigate the roles of service quality, perceived green value, customer satisfaction, and perceived pleasure in determining customer loyalty to smart DBSS. In order to achieve this objective, the target population for this study was identified as all users who had ridden smart DBSS in last three weeks. Determining an appropriate sample size is very important for ensuring the quality and rigor of any study. According to Hair, Hult, Ringle, and Sarstedt (2014) and Barclay, Higgins, and Thompson (1995), there is a 10-times rule where the minimum sample should be 10 times the largest number of structural paths directed at a particular construct in a structural model. The structural model of this study involves five constructs (i.e., one independent variable, three mediators, and one dependent variable) and eight structural paths; according to the 10-times rule criterion, the minimum sample size should be 80 respondents.

A survey was implemented from May 1 to June 29, 2017. The questionnaire was distributed in public areas, such as parks, malls, libraries, and coffee shops, in Chengdu, the economic center of western China. As of April 15, 2017, there were more than 500,000 smart bikes and 4.6 million registered users in Chengdu (SCnews, 2017). A definition and example of smart DBSS were first 
explained to the target respondents, and they were then asked if they had used smart DBSS in the last three weeks. If the answer was positive, the respondents were invited to complete the survey. They were told to complete the questionnaire according to their feelings about their favorite smart DBSS brand or frequently used bike brands. A total of 400 individuals were invited to participate face to face. We received 380 completed questionnaires (95\% response rate), scrutinized all responses, and dropped those with too much missing information. As a result, we obtained 374 valid responses. Table 1 shows all the demographic variables for this study. Among the participants, $49.5 \%$ were male and $50.5 \%$ were female. A majority (84.5\%) were under 36 years of age. Almost $90.6 \%$ of the respondents had received a university education. The main population characteristics of the sample are very similar to in the study by Wang et al. (2018), who investigated the impact of consumers' values and attitudes on the adoption of bike sharing in China, and the report on smart DBSS by TalkingData (2016), a leading third-party data intelligence service provider in China. Thus, the sample of this study is representative and unbiased.

Table 1

\section{Demographics of respondents}

\begin{tabular}{|c|c|c|c|c|c|}
\hline Demographics & Frequency & Percentage (\%) & Demographics & Frequency & Percentage (\%) \\
\hline Gender & & & Walking & 123 & 32.9 \\
\hline Male & 185 & 49.5 & Private bicycle & 48 & 12.8 \\
\hline Female & 189 & 50.5 & Private car & 37 & 9.9 \\
\hline Age (years) & & & Public transport & 154 & 41.2 \\
\hline Below 18 & 16 & 4.3 & Taxi & 8 & 2.1 \\
\hline $18-25$ & 237 & 63.4 & Other & 4 & 1.1 \\
\hline $26-35$ & 63 & 16.8 & The Purpose of Using Smart DBSS & & \\
\hline $36-45$ & 45 & 12.0 & Recreation & 60 & 16.0 \\
\hline $46-65$ & 10 & 2.7 & Commuter journey & 41 & 11.0 \\
\hline 66 and above & 3 & 0.8 & Campus trip & 170 & 45.5 \\
\hline Education & & & Short trip & 79 & 21.1 \\
\hline High School or below & 35 & 9.4 & Other & 24 & 6.4 \\
\hline University student & 219 & 58.6 & Monthly Income (RMB) & & \\
\hline Bachelor & 100 & 26.7 & Less than 1,000 & 176 & 47.1 \\
\hline Master or above & 20 & 5.3 & 1,000 to 2,999 & 79 & 21.1 \\
\hline Occupation & & & 3,000 to 5,999 & 78 & 20.9 \\
\hline Self-employed & 30 & 8.0 & 6,000 to 9,999 & 30 & 8.0 \\
\hline Business & 64 & 17.1 & More than 10,000 & 11 & 2.9 \\
\hline Public servant & 22 & 5.9 & Use Frequency (Weekly) & & \\
\hline Education or research & 20 & 5.3 & 1 or less than 1 & 37 & 9.9 \\
\hline Student & 226 & 60.4 & $2-5$ & 130 & 34.8 \\
\hline Other & 12 & 3.2 & 6-10 & 166 & 44.3 \\
\hline Main Mode of Travel & & & More than 10 & 41 & 11.0 \\
\hline
\end{tabular}




\section{Results}

The structural equation modeling (SEM) technique was performed to examine the research model in this study. There are two distinct types of SEM approaches: the covariance-based approach and the variance-based approach. Compared with covariance-based structural equation modeling tools, the partial least squares (PLS) method, a variance-based approach, is very suitable for studies with small sample sizes without requiring normal distribution (Chin, 1998). PLS is also a better technique for dealing with both the formative and reflective models (Akter, D'Ambra, \& Ray, 2013; Barnes, 2011). In this study, based on the Kolmogorov-Smirnov test, the data were not divided normally $(p<0.01)$. For this reason, PLS was appropriate for our study. The research model was validated via the two-step analysis procedures of the measurement and structural models (Hair, Anderson, Tatham, \& Black, 1998).

\section{I Common method variance}

The issue of common method deviation might influence the validity of the research with its perceptual and single-source data (Podsakoff, Mackenzie, Lee, \& Podsakoff, 2003). In our study, common method deviation was examined using Harman's single factor test (Podsakoff \& Organ, 1986). The analysis indicated that all the items could be classified into five factors, and the first factor explained only $17.76 \%$ of the variance. Thus, no one factor can explain the majority of the variance. These results suggested that common method deviation was not an important consideration in this research.

\subsection{Inspecting the measurement model}

The measurement model was estimated to ensure the appropriate use of psychological instruments, including reliability, convergent validity, and discriminant validity.

First, we used Cronbach's alpha to test reliability. Reliability is the extent to which the observed variables test the "true" value and if they are "error free." As shown in Table 2, the Cronbach's alpha (reliability) ranges from 0.846 to 0.906 . Because the overall reliability of the measurement was above 0.7 , the measurement instrument showed sufficient internal consistency (Bagozzi \& Yi, 1988; Premkumar \& Roberts, 1999).

Second, a confirmatory factor analysis (CFA) was used to measure validity, which includes convergent validity and discriminant validity. Convergent validity measures if items reflect their corresponding factors effectively, and discriminant validity measures if two factors are statistically different. Table 2 shows the standardized item loadings, average variance extracted (AVE), and composite reliability (CR). As shown in the table, all item loadings are larger than 0.7 (SQ1 is close to 0.7$)$. The $t$-values illustrated that all loadings are significant at $p<0.001$. All AVEs exceed 0.5, and all CRs exceed 0.7. Thus, the scale has good convergent validity (Gefen, Straub, \& Boudreau, 2000). To examine the discriminant validity, we compared the square root of the AVE and factor correlation coefficients. As shown in Table 3, the square root of the AVE is significantly larger than the correlation coefficients for each factor. Thus, it reflects good discriminant validity (Gefen et al., 2000). 
Table 2

Standardized item loadings, AVE, CR, and alpha values

\begin{tabular}{|c|c|c|c|c|c|}
\hline Factor & Item & Standardized loading & AVE & CR & $\begin{array}{c}\text { Cronbach's } \\
\text { alpha }\end{array}$ \\
\hline \multirow{4}{*}{ Perceived green value } & PGV1 & 0.811 & \multirow{4}{*}{0.684} & \multirow{4}{*}{0.896} & \multirow{4}{*}{0.846} \\
\hline & PGV2 & 0.865 & & & \\
\hline & PGV3 & 0.868 & & & \\
\hline & PGV4 & 0.758 & & & \\
\hline \multirow{5}{*}{ Service quality } & SQ1 & 0.694 & \multirow{5}{*}{0.643} & \multirow{5}{*}{0.900} & \multirow{5}{*}{0.861} \\
\hline & SQ2 & 0.800 & & & \\
\hline & SQ3 & 0.836 & & & \\
\hline & SQ4 & 0.827 & & & \\
\hline & SQ5 & 0.844 & & & \\
\hline \multirow{3}{*}{ Perceived pleasure } & PP1 & 0.883 & \multirow{3}{*}{0.822} & \multirow{3}{*}{0.932} & \multirow{3}{*}{0.891} \\
\hline & PP2 & 0.922 & & & \\
\hline & PP3 & 0.913 & & & \\
\hline \multirow{3}{*}{ Customer satisfaction } & CS1 & 0.910 & \multirow{3}{*}{0.842} & \multirow{3}{*}{0.941} & \multirow{3}{*}{0.906} \\
\hline & CS2 & 0.929 & & & \\
\hline & $\mathrm{CS} 3$ & 0.914 & & & \\
\hline \multirow{3}{*}{ Customer loyalty } & CL1 & 0.918 & \multirow{3}{*}{0.808} & \multirow{3}{*}{0.927} & \multirow{3}{*}{0.881} \\
\hline & CL2 & 0.923 & & & \\
\hline & CL3 & 0.854 & & & \\
\hline
\end{tabular}

Table 3

The square root of AVE, factor correlation coefficients, and Q2

\begin{tabular}{lcccccc}
\hline & $\mathbf{Q 2}$ & $\mathbf{C L}$ & $\mathbf{P P}$ & $\mathbf{C S}$ & $\mathbf{P G V}$ & SQ \\
\hline CL & 0,443 & $\mathbf{0 , 8 9 9}$ & & & & \\
PP & 0,195 & 0,679 & $\mathbf{0 , 9 0 6}$ & & $\mathbf{0 , 9 1 8}$ & \\
CS & 0,350 & 0,594 & 0,523 & 0,431 & $\mathbf{0 , 8 2 7}$ & \\
PGV & 0,066 & 0,517 & 0,425 & 0,586 & 0,332 & $\mathbf{0 , 8 0 2}$ \\
SQ & & 0,471 & 0,501 & 0,586 \\
\hline
\end{tabular}

Note: Diagonal elements are the square root of the average variance extracted from each construct; Pearson correlations are shown below the diagonal. $\mathrm{SQ}=$ service quality, $\mathrm{PGV}=$ perceived green value, $\mathrm{CS}=$ customer satisfaction, $\mathrm{PP}=$ perceived pleasure, and CL = customer loyalty.

\subsection{Investigating the structural model}

The investigation results of the structural model are shown in Table 4 and illustrated in Figure 2. The results provide the integrated explanatory power, assessed path coefficients (all significant paths are indicated with asterisks), f square, and associated $t$-values of each path in this model. The bootstrapping re-sampling procedure was employed to test path significance. All hypotheses are supported. The relevant explanations of these outcomes are further elaborated on in the discussion section. 


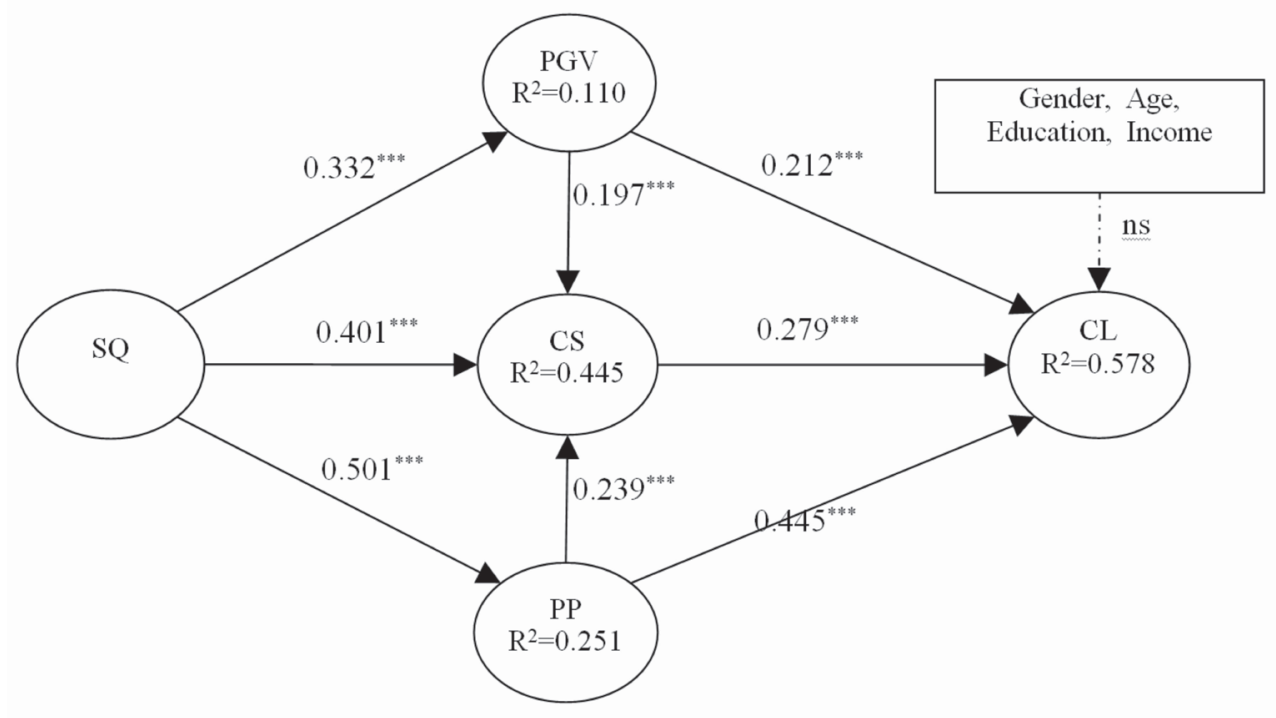

Figure 2. Results of the research model tests.

Notes: ${ }^{* * *} p<0.001,{ }^{* *} p<0.01$, and ${ }^{*} p<0.05$. SQ $=$ service quality, PGV = perceived green value, $\mathrm{CS}=$ customer satisfaction, $\mathrm{PP}=$ perceived pleasure, and $\mathrm{CL}=$ customer loyalty.

Table 4

\section{Results of hypothesis testing}

\begin{tabular}{ccccccc}
\hline Hypothesis & Structural path & Path coefficients & T statistics & P value & Supported & f2 \\
\hline H1 & SQ->PGV & 0.332 & 8.034 & 000 & Yes & 0.124 \\
H2 & SQ->CS & 0.401 & 8.153 & 000 & Yes & 0.212 \\
H3 & SQ->PP & 0.501 & 11.345 & 000 & Yes & 0.336 \\
H4 & PGV->CS & 0.197 & 3.659 & 000 & Yes & 0.056 \\
H5 & PGV $>$ CL & 0.212 & 4.771 & 000 & Yes & 0.080 \\
H6 & PP->CS & 0.239 & 4.094 & 000 & Yes & 0.069 \\
H7 & PP->CL & 0.445 & 7.725 & 000 & Yes & 0.308 \\
H8 & CS->CL & 0.279 & 5.520 & 000 & Yes & 0.121 \\
\hline
\end{tabular}

Notes: $\mathrm{SQ}=$ service quality, $\mathrm{PGV}=$ perceived green value, $\mathrm{CS}=$ customer satisfaction, $\mathrm{PP}=$ perceived pleasure, and $\mathrm{CL}=$ customer loyalty.

The results revealed that service quality has a direct positive effect on perceived green value $(\beta=0.332, p<0.001)$, customer satisfaction $(\beta$ $=0.401, p<0.001)$, and perceived pleasure $(\beta=$ $0.501, p<0.001)$. Therefore, $\mathrm{H} 1, \mathrm{H} 2$, and $\mathrm{H} 3$ are supported. Perceived green value has a direct positive effect on both customer satisfaction $(\beta=$ $0.197, p<0.001)$ and customer loyalty $(\beta=0.212$, $p<0.001)$. Thus $\mathrm{H} 4$ and $\mathrm{H} 5$ are supported. Perceived pleasure has a direct positive effect on both customer satisfaction $(\beta=0.239, p<0.001)$ and customer loyalty $(\beta=0.445, p<0.001)$; thus, $\mathrm{H} 6$ and $\mathrm{H} 7$ are supported. Customer satisfaction has a direct positive effect on customer loyalty ( $\beta$ $=0.279, p<0.001)$; therefore, H8 is supported. In addition, the results of this study indicate that there are no confounding effects of the control variables (gender, age, education, and income) on loyalty to smart DBSS.

The model illustrates that $11.0 \%$ of the variance exists in perceived green value, $44.5 \%$ exists in customer satisfaction, $25.1 \%$ exists 
in perceived pleasure, and $57.8 \%$ is related to customer loyalty. This result indicates that the proposed conceptual model has adequate explanatory significance (Farooq, Salam, Fayolle, Jaafar, \& Ayupp, 2018). As shown in Table 3, all Q2 values are larger than zero. This result shows that the endogenous constructs (i.e., perceived green value, customer satisfaction, perceived pleasure, and customer loyalty) involved in this study have strong predictive relevance (Chin, 2010). The standardized root mean square residual (SRMR) value of this model is 0.065 (less than 0.08$)$, and the goodness of fit $(\mathrm{GoF})$ value is 0.513 (more than 0.36 ), which indicates a very good model fit ( $\mathrm{Hu} \&$ Bentler, 1998; Wetzels, Odekerken-Schröder, \& Oppen, 2009).

On the basis of the above analysis, it is concluded that both the measurement model and the structural model are validated. Moreover, these results show that the proposed theoretical model of this study has significant predictive relevance and explanatory power.

\section{Discussion}

The purpose of this study is to explore the factors that affect a user's continued intentions to use smart DBSS. To accomplish this, this work proposes a research model with five concepts and examines their causal relationships in the field of smart DBSS. The results show that customer loyalty was found to be the dependent construct generated by the other four preceding independent dimensions. Perceived green value, customer satisfaction, and perceived pleasure are also appraised as partial mediators between service quality and customer loyalty.

The findings of the current study indicate that service quality is an important determinant of perceived green value, customer satisfaction, and perceived pleasure. First, service quality has a positive relationship with perceived green value $(\mathrm{H} 1)$. This finding is similar to previous studies by Benjamin et al. (2015) and Lai and Chen (2011). They deemed that good service quality can help improve passengers' sense of value of the public transit system. This study further confirms that excellent service quality can not only enhance users' understanding of the value of public transport, but also enhance their perception of the environmental value generated by public transport. That is to say, if smart DBSS firms provide good services to users, it will enhance their perception of environmental value. Second, service quality has a significant impact on customer satisfaction (H2). This finding is consistent with prior studies by Lai and Chen (2011) and Mugion et al. (2017). They believe that passenger satisfaction with public transport is closely related to the service quality provided by the firms. In the smart DBSS context, service quality is measured as user evaluations of the service attributes of smart DBSS, such as the general characteristics of the bikes, firm, and employees. When the service attributes meet or exceeds the users' expectations, their satisfaction will increase, and they will be satisfied with the services of the smart DBSS firm. Moreover, everyone has a responsibility to protect the environment, and smart DBSS firms provide customer value-oriented service quality to meet users' demands for environmental protection. When users participate in green traffic, their perception of environmental value is improved, and, in turn, their satisfaction is also increased (H4) (Lai et al., 2009; Sumaedi et al., 2016). Third, service quality has a significant effect on perceived pleasure (H3). This result is similar to that of a previous study by Kim and Moon (2009). They argued that some special service can help an individual feel good, happy, or satisfied. This study confirms that some special service (such as appealing bicycles, a personalized service, and timely responses) provided by smart DBSS firms can motivate users' positive beliefs, which helps users develop a similarly positive feeling (pleasure). When the users' pleasure is increased, they will also be satisfied with the services of smart DBSS firms (H6) (Bigné et al., 2005). 
The findings of this study also show that customer loyalty is directly determined by three factors: perceived green value, customer satisfaction, and perceived pleasure. First, there is a significant positive relationship between perceived green value and customer loyalty (H5). This finding is consistent with prior studies by Hazen et al. (2015), Chen (2017), and Wang et al. (2018). They deemed that perceived (green) value has an impact on consumer adoption intentions regarding BSS. That is to say, when users realize the environmental value of smart DBSS, such as reducing congestion, emissions, and energy consumption, they believe that their environmentfriendly behaviors correspond to environmental promise and performance. Their willingness to use smart DBSS over the long term will be enhanced, and they will recommend the services to their friends and relatives due to its environmental value. Second, customer satisfaction has a positive impact on customer loyalty (H8). The conclusion suggests that efforts to improve users' satisfaction could significantly increase customer loyalty to smart DBSS. It also means that a user who is satisfied with green transportation is likely to utilize it again and recommend it to other users. This point is confirmed by Chou et al. (2014), Han et al. (2017), and Mugion et al. (2017). Third, perceived pleasure positively influences customer loyalty (H7). This finding is consistent with those reported in previous studies by Chen (2016a, 2016b), Gohm and Clore (2000), and Kim and Moon (2009). Gohm and Clore (2000) confirmed that a person who feels a higher level of pleasure in activities is more likely to frequently participate in the corresponding activities. That is to say, if the users deem that using smart DBSS is interesting and can help them relax and forget their troubles, they will continue to use smart DBSS for a long time and advocate this green mode of transportation.

More importantly, in the research model, the coefficient between service quality and perceived pleasure, of 0.501 , is the most significant compared to the other two pairs (service quality and perceived green value, and service quality and customer satisfaction), and the coefficient between perceived pleasure and customer loyalty, of 0.449 , is also the most significant compared to the other two pairs (perceived green value and customer loyalty, and customer satisfaction and customer loyalty). This result indicates that the role of perceived pleasure is very important to understand users' behavior in terms of using smart DBSS, and the quality-pleasure-loyalty (QPL) relationship should be taken seriously.

\section{Implications and limitations}

\section{I Implications for researchers}

Overall, this study makes several important contributions to enrich the existing literature on user behavior related to smart DBSS. First, the study provides a new perspective from which to examine users' green travel behavior in the smart DBSS field. As the fourth generation of BSS, smart DBSS have attracted little research from scholars, until recently. The limited research on smart DBSS has mainly explored the effect and marketing influence of the service using objective data, and few studies have investigated smart DBSS users' behavior from a psychological perspective via empirical testing. This study attempted to fill this gap and to propose a conceptual model to empirically investigate users' loyalty to smart DBSS. The research provides an integrated framework for scholars who engage in similar research in the future.

Second, the contribution of this study is that it identifies the role of service quality as an important stimulus. Although previous research has suggested that perceived pleasure and perceived green value have a significant effect on green loyalty to use BSS, what factors trigger perceptive values and perceived pleasure remain unclear. This study uses service quality to examine the consumer's overall perception of service performance based on five dimensions, tangibles, reliability, responsiveness, assurance, and empathy, and it tests the relationship among 
perceived pleasure, perceived green value, customer satisfaction, and service quality. The study confirms that service quality acts as a vital stimulus that drives perceived pleasure, perceived green value, and customer satisfaction.

Third, another contribution of this study is that it identifies the intermediary role of perceived pleasure. Although previous studies have verified the intermediary role of perceived value and customer satisfaction between service quality and user behavior intention, the intermediary role of perceived pleasure remains unclear. This study confirms that perceived pleasure not only has the biggest effect on customer loyalty compared to perceived green value and customer satisfaction, but also acts as an excellent mediator, which can expand the effect from service quality to customer loyalty. The quality-pleasure-loyalty (QPL) path is clearly superior to other paths. Thus, our study enriches the literature on user behavior related to smart DBSS.

\subsection{Implications for practitioners}

Several practical implications can be drawn from the key findings of this study. First, managers of smart DBSS firms should pay attention to the role of perceived pleasure when developing marketing strategies. On one hand, firms should ensure true and real enjoyment for users when they use bikes. Firms can invest more effort to help users feel higher levels of pleasure and make them think that using smart DBSS is interesting and can help them relax and forget their troubles. If users feel pleasure in using smart DBSS, they will be loyal to these services. On the other hand, the company should provide pleasureoriented service quality to enhance users' pleasant feelings. Some special services, such as providing appealing bicycles and a personalized service, can be implemented to help users experience a pleasant feeling, which can also enhance their loyalty to smart DBSS.

Second, managers of smart DBSS firms could address customer satisfaction in their business strategies. Users' behavioral loyalty significantly relies on their satisfaction. To enhance passenger satisfaction, service quality must be considered. Companies should strive to identify the service attributes that users are most concerned about and constantly improve service quality, which is a prerequisite to obtaining users' satisfaction. According to the results of this study, service attributes such as dependable firms, reliable online customer service staff, and timely responses significantly influence users' satisfaction. These findings can provide useful information for the smart firms in their efforts to prioritize the important service attributes and ensure their service quality meets or exceeds user expectations.

Third, firms should also pay attention to the role of perceived green value, which can motivate users' loyalty to smart DBSS. On one hand, service providers can use some incentives and free strategies (such as free rides) to attract and encourage more users to experience smart DBSS so that they understand the real green value. Firms can also increase related advertising to emphasize the advantages of using smart DBSS (e.g., health benefits, emissions reductions, reduced congestion, and flexible mobility) and the importance of protecting the natural environment. On the other hand, as service quality has a positive relationship with perceived green value, firms can also provide services related to enhancing user value to guide users' perceptions of the green value of smart DBSS.

\subsection{Limitations and future research directions}

Our research does have some limitations. First, we conducted the research in China, where smart DBSS are developing rapidly but are still in their infancy. Thus, the results need to be examined further in other countries and regions. Second, even though our research explored the hypotheses through questionnaires, the survey only generated cross-sectional results and did not examine the dynamic process in different periods. Third, this study employs service quality to 
examine consumers' overall perception of service performance based on five dimensions - tangibles, reliability, responsiveness, assurance, and empathy - and the effect of each dimension should be verified by further studies. In addition, the results of the study indicate that there are no confounding effects of gender, age, education, and income on loyalty to smart DBSS. This finding is very similar to those of previous studies (Wang et al., 2018). However, Wang et al. (2018) also argued that age has significant effects on adoption intention to use BSS. Thus, this point should be explored in further research. Despite the abovementioned limitations, we believe that this study contributes to further understanding behaviors related to the adoption of green transportation and will provide a set of guidelines for smart DBSS firms.

\section{References}

Akter, S., D’Ambra, J., \& Ray, P. (2013). Development and validation of an instrument to measure user perceived service quality of mHealth. Information \& Management, 50(4), 181-195.

An, M., \& Noh, Y. (2009). Airline customer satisfaction and loyalty: Impact of in-flight service quality. Service Business, 3(3), 293-307.

Anderson, E. W., \& Fornell, C. (2000). Foundations of the American customer satisfaction index. Total quality management, 11(7), 869-882.

Bagozzi, R. P., \& Yi, Y. (1988). On the evaluation of structural equation models. Journal of the academy of marketing science, 16, 74-94.

Barclay, D., Higgins, C., \& Thompson, R.,. (1995). The partial least squares (PLS) approach to causal modeling: Personal computer adoption and use as an illustration (with commentaries). Technol. Stud, 2.

Barnes, S. J. (2011). Understanding use continuance in virtual worlds: Empirical test of a research model. Information \& Management, 48(8), 313-319. doi: https://doi.org/10.1016/j. im.2011.08.004

Bigné, J. E., Andreu, L., \& Gnoth, J. (2005). The theme park experience: An analysis of pleasure, arousal and satisfaction. Tourism Management, 26(6), 833-844.

Bishop, W. R., Jr. (1984). Competitive intelligence. Progressive Grocer, 63(3), 19-20.

Bordagaray, M., Dell'Olio, L., Fonzone, A., \& Ibeas, Á. (2016). Capturing the conditions that introduce systematic variation in bikesharing travel behavior using data mining techniques. Transportation Research Part C Emerging Technologies, 71, 231-248.

Campbell, A. A., Cherry, C. R., Ryerson, M. S., \& Yang, X. (2016). Factors influencing the choice of shared bicycles and shared electric bikes in Beijing. Transportation Research Part C, 67, 399-414.

Caro, L. M., \& García, J. A. M. (2008). Developing a multidimensional and hierarchical service quality model for the travel agency industry. Tourism Management, 29(4), 706-720.

Chen, S. Y. (2016a). Green helpfulness or fun? Influences of green perceived value on the green loyalty of users and non-users of public bikes. Transport Policy, 47, 149-159.

Chen, S. Y. (2016b). Using the sustainable modified TAM and TPB to analyze the effects of perceived green value on loyalty to a public bike system. Transportation Research Part A Policy \& Practice, $88,58-72$.

Chen, S. Y. (2017). Eco-friendly value or others' environmental norms? Arguing the environmental using psychology of bike-sharing for the general public. Transportation Letters the International Journal of Transportation Research, 11(8), 425-435.

Chen, S. Y., \& Lu, C. C. (2016). A Model of Green Acceptance and Intentions to Use Bike- 
Sharing: YouBike Users in Taiwan. Networks \& Spatial Economics, 16(4), 1103-1124.

Chin, W. W. (1998). The partial least squares approach to structural equation modeling. Modern methods for business research, 295(2), 295-336.

Chin, W. W. (2010). How to write up and report PLS analyses. Handbook of Partial Least Squares. 655-690.

Chou, J.-S., \& Kim, C. (2009). A structural equation analysis of the QSL relationship with passenger riding experience on high speed rail: An empirical study of Taiwan and Korea. Expert Systems with Applications, 36(3), 6945-6955.

Chou, P.-F., Lu, C.-S., \& Chang, Y.-H. (2014). Effects of service quality and customer satisfaction on customer loyalty in high-speed rail services in Taiwan. Transportmetrica A: Transport Science, 10(10), 917-945.

Chou, P. F., \& Lu, C. S. (2009). Assessing service quality, switching costs and customer loyalty in home-delivery services in Taiwan. Transport Reviews, 29(6), 741-758.

Chou, S.-W., Min, H.-T., Chang, Y.-C., \& Lin, C.T. (2010). Understanding continuance intention of knowledge creation using extended expectationconfirmation theory: An empirical study of Taiwan and China online communities. Behaviour \& Information Technology, 29(6), 557-570.

Cronin , J. J., Jr., \& Taylor, S. A. (1992). Measuring service quality: A reexamination and extension. The journal of marketing,56(3)5-68.

Das, G. (2013). The Effect of Pleasure and Arosal on Satisfaction and Word-of-Mouth: An Empirical Study of the Indian Banking Sector. Vikalpa, 38(2), 95-104.

Farooq, M. S., Salam, M., Fayolle, A., Jaafar, N., \& Ayupp, K. (2018). Impact of service quality on customer satisfaction in Malaysia airlines: A PLS-SEM approach. Journal of Air Transport Management, , 67,169-180.

Fernández-Heredia, Á., Monzón, A., \& Jara-Díaz, S. (2014). Understanding cyclists' perceptions, keys for a successful bicycle promotion. Transportation Research Part A: Policy and Practice, 63, 1-11. doi: https://doi.org/10.1016/j.tra.2014.02.013

Fishman, E., Washington, S., \& Haworth, N. (2012). Barriers and facilitators to public bicycle scheme use: A qualitative approach. Transportation Research Part F Psychology \& Behaviour, 15(6), 686-698.

Fishman, E., Washington, S., \& Haworth, N. (2014). Bike Share: A Synthesis of the Literature. Urban Transport of China, 33(2), 148-165.

Fishman, E., Washington, S., Haworth, N., \& Watson, A. (2015). Factors influencing bike share membership: An analysis of Melbourne and Brisbane. Transportation Research Part A, 71, 17-30.

Gefen, D., Straub, D. W., \& Boudreau, M. C. (2000). Structural equation modeling and regression: Guidelines for research practice. Communications of the Association for Information Systems, 4(7). doi: 10.17705/1CAIS.00407

Gohm, C. L., \& Clore, G. L. (2000). Individual differences in emotional experience: Mapping available scales to processes. Personality and Social Psychology Bulletin, 26(6), 679-697.

Grönroos, C. (1984). A service quality model and its marketing implications. European Journal of marketing, 18(4), 36-44.

Grönroos, C. (1988). Service quality: The six criteria of good perceived service. Review of business, 9(3), 10-13.

Grönroos, C. (1990). Relationship approach to marketing in service contexts: The marketing 
and organizational behavior interface. Journal of Business Research, 20(1), 3-11.

Guo, Y., Zhou, J., Wu, Y., \& Li, Z. (2017). Identifying the factors affecting bike-sharing usage and degree of satisfaction in Ningbo, China. Plos One, 12(9). doi: https://doi.org/10.1371/journal. pone. 0185100

Hair, J. F., Anderson, R. E., Tatham, R. L., \& Black, W. C. (1998). Multivariate data analysis (5th ed.). New York:All Publications.

Hair, J. F., Jr., Hult, G. T. M., Ringle, C. M. R., \& Sarstedt, M. (2014). A primer on partial least squares structural equation modeling (PLS-SEM). Washington DC: SAGE Publications, Inc.

Han, H., Meng, B., \& Kim, W. (2017). Biketraveling as a growing phenomenon: Role of attributes, value, satisfaction, desire, and gender in developing loyalty. Tourism Management, 59, 91-103.

Harris, L. C., \& Goode, M. M. H. (2004). The four levels of loyalty and the pivotal role of trust: A study of online service dynamics. Journal of Retailing, 80(2), 139-158.

Hazen, B., Overstreet, R., \& Wang, Y. (2015). Predicting Public Bicycle Adoption Using the Technology Acceptance Model. Sustainability, 7(11), 14558-14573. doi: 10.3390/su71114558

Hu, L.-t., \& Bentler, P. M. (1998). Fit indices in covariance structure modeling: Sensitivity to underparametrized model misspesification. Psychological Methods, 3(4), 424-453.

Hyun, S. S., \& Kang, J. (2014). A better investment in luxury restaurants: environmental or non-environmental cues? International Journal of Hospitality Management, 39, 57-70.

International Energy Agency. (2016, june 27). Energy and Air Pollution. from http://www.iea. org/newsroom/news/2016/june/energy-and-airpollution.html

iiMedia. (2017). 2017 China smart DBSS summer market special report. Retrieved from http://www. iimedia.cn/59210.html

iResearch. (2017). China Bicycle sharing industry Report. Retrieved from http://www.iresearch. com.cn/

Institute for Transportation \& Development Policy (2015). China bike sharing. Retrieved from http://www.publicbike.net/

Izogo, E. E., \& Ogba, I.-E. (2015). Service quality, customer satisfaction and loyalty in automobile repair services sector. International Journal of Quality \& Reliability Management, 32(3), 250-269.

Jain, S. K., \& Gupta, G. (2004). Measuring service quality: Servqual vs. servperf scales. Vikalpa, 29(2), 25-38.

Johnson, M. D., Anderson, E. W., \& Fornell, C. (1995). Rational and adaptive performance expectations in a customer satisfaction framework. Journal of consumer research, 21(4), 695-707.

Kaplan, S., Manca, F., Nielsen, T. A. S., \& Prato, C. G. (2015). Intentions to use bike-sharing for holiday cycling: An application of the theory of planned Behavior. Tourism Management, 47, 34-46.

Khatibi, A. A., Ismail, H., \& Thyagarajan, V. (2002). What drives customer loyalty: An analysis from the telecommunications industry. Journal of Targeting, Measurement and Analysis for Marketing, $11,34-44$.

Kim, W. G., \& Moon, Y. J. (2009). Customers' cognitive, emotional, and actionable response to the servicescape: A test of the moderating effect of the restaurant type. International Journal of Hospitality Management, 28(1), 144-156. 
Kotler, Philip, Keller, \& Lane, K. (2006). Marketing management (12th ed.). Indonesia: Kondisi ekonomi.

Kotler, P., \& Singh, R. (1981). Marketing warfare in the 1980s. The Journal of Business Strategy, 1, $30-41$.

Kuo, Y.-F., Wu, C.-M., \& Deng, W.-J. (2009). The relationships among service quality, perceived value, customer satisfaction, and post-purchase intention in mobile value-added services. Computers in human behavior, 25(4), 887-896.

Lai, F., Griffin, M., \& Babin, B. J. (2009). How quality, value, image, and satisfaction create loyalty at a Chinese telecom. Journal of Business Research, 62(10), 980-986.

Lai, T. L. (2004). Service quality and perceived value's impact on satisfaction, intention and usage of short message service (SMS). Information Systems Frontiers, 6(4), 353-368.

Lai, W.-T., \& Chen, C.-F. (2011). Behavioral intentions of public transit passengers-The roles of service quality, perceived value, satisfaction and involvement. Transport Policy, 18(2), 318-325.

Lien, C.-H., Cao, Y., \& Zhou, X. (2017). Service quality, satisfaction, stickiness, and usage intentions: An exploratory evaluation in the context of WeChat services. Computers in human behavior, 68, 403-410.

Mateo-Babiano, I., Bean, R., Corcoran, J., \& Pojani, D. (2016). How does our natural and built environment affect the use of bicycle sharing? Transportation Research Part A Policy \& Practice, 94, 295-307.

Mugion, R. G., Toni, M., Raharjo, H., Pietro, L. D., \& Sebathu, S. P. (2017). Does the service quality of urban public transport enhance sustainable mobility? Journal of Cleaner Production, 174, 1566-1587
Optimising Bike sharing in European Cities (2011). Optimising Bike sharing in European Cities. Retrieved from https://www.researchgate. net/project/OBIS-Optimising-Bike-sharing-inEuropean-Cities

Oliver, R. L. (1980). A cognitive model of the antecedents and consequences of satisfaction decisions. Journal of marketing research,17(4) 460-469.

Oliver, R. L. (1981). Measurement and evaluation of satisfaction processes in retail settings. Journal of Retailing, 57(3), 25-48

Oliver, R. L. (2010). Satisfaction: A behavioral perspective on the consumer. Asia Pacific Journal of Management, 2(2), 285-286.

Parasuraman, A., Zeithaml, V. A., \& Berry, L. L. (1988). SERVQUAL: A multiple-item scale for measuring consumer perceptions of service quality. Journal of Retailing, 64(1), 12-37.

Podsakoff, P. M., Mackenzie, S. B., Lee, J. Y., \& Podsakoff, N. P. (2003). Common method biases in behavioral research: A critical review of the literature and recommended remedies. J Appl Psychol, 88(5), 879-903.

Podsakoff, P. M., \& Organ, D. W. (1986). Selfreports in organizational research: Problems and prospects. Journal of Management, 12(4), 531544.

Premkumar, G., \& Roberts, M. (1999). Adoption of new information technologies in rural small businesses. Omega, 27(4), 467-484.

ResearchInChina. (2017). China Bicycle Sharing Industry Report. Retrivied from http://www. researchinchina.com/

Rezvani, Z., Jansson, J., \& Bodin, J. (2015). Advances in consumer electric vehicle adoption research: A review and research agenda. Transportation Research Part D: Transport and environment 34(34), 122-136. 
Russell, J. A. (1979). Affective space is bipolar. Journal of personality and social psychology, 37(3), 345.

SCnews. (2017). Chengdu Bike Sharing Systems. Retrivied from http://scnews.newssc.org/ syst1qem/20170505/000775783.html

Shaheen, S., Zhang, H., Martin, E., \& Guzman, S. (2011). Hangzhou public bicycle: Uderstanding early adoption and Behavioral esponse to bikesharing In Hangzhou, China. Transportation Research Record Journal of the Transportation Research Board, 2247(1),33-41.

Shaheen, S. A., Guzman, S., \& Zhang, H. (2010). Bikesharing in Europe, the Americas, and Asia: Past, present, and future. Transportation Research Record Journal of the Transportation Research Board, 2143(1), 159-167.

Shen, Y., Zhang, X., \& Zhao, J. (2018). Understanding the usage of dockless bike sharing in Singapore. International Journal of Sustainable Transportation, 12(9), 686-700.

Sheth, J. D., Newman, B. I., \& Gross, B. L. (1991). Consumption Values and Market Choices: Theory and Applications. Journal of Marketing Research, 29(4), 487-489.

Shi, J.-g., Si, H., Wu, G., Su, Y., \& Lan, J. (2018). Critical Factors to Achieve Dockless Bike-Sharing Sustainability in China: A Stakeholder-Oriented Network Perspective. sustainability, 10, 1-16.

Straub, D., Boudreau, Marie-claude, \& Gefen, D.(2004). Validation Guidelines for IS Positivist Research. Communications of the Association for Information Systems.13(24). DOI:10.17705/1CAIS.01324.

Sumaedi, S., Bakti, I. G. M. Y., Rakhmawati, T., Astrini, N. J., Widianti, T., \& Yarmen, M. (2016). Factors influencing public transport passengers' satisfaction: A new model. Management of Environmental Quality: An International Journal, 27(5), 585-597.
Sun, Y., Mobasheri, A., Hu, X., \& Wang, W. (2017). Investigating impacts of environmental factors on the cycling behavior of bicycle-sharing users. sustainability, 9(6), 1-12

TalkingData. (2016). 2016 Bike-sharing population analysis report. Retrieved from http:// mi.talkingdata.com/report-detail.html?id=462

Tang, Y., Pan, H., \& Fei, Y. (2017). Research on users' frequency of ride in Shanghai minhang bike-sharing system. Transportation Research Procedia, 25, 4983-4991.

Van de Vijver, F. J., \& Leung, K. (1997). Methods and data analysis for cross-cultural research (Vol.1) Thousand Oaks: Sage.

Van der Wiele, T., Boselie, P., \& Hesselink, M. (2002). Empirical evidence for the relationship between customer satisfaction and business performance. Managing Service Quality: An International Journal, 12(3), 184-193.

Vinita, K., \& Kumar, D. S., (2012). Impact of service quality on satisfaction in the Indian banking sector. IUP Journal of Marketing Management, 11(3), 38-47.

Wang, Y., Douglas, M. A., Hazen, B. T., \& Dresner, M. (2018). Be green and clearly be seen: How consumer values and attitudes affect adoption of bicycle sharing. Transportation Research Part F: Traffic psycology and Behaviour, 58, 730-742.

Wetzels, M., Odekerken-Schröder, G., \& Oppen, C. V. (2009). Using PLS Path Modeling for Assessing Hierarchical Construct Models: Guidelines and empirical illustration. Mis Quarterly, 33(1), 177-195.

Winters, M., Sims-Gould, J., Franke, T., \& McKay, H. (2015). "I grew up on a bike”: Cycling and older adults. Journal of Transport \& Health, 2(1), 58-67. doi: https://doi.org/10.1016/j. jth.2014.06.001 
YIN (2017). Bankrupt OBSs enterprises. Retrieved from https://www.sohu. com/a/213947896_99924630

Zeithaml, V. A. (1988). Consumer perceptions of price, quality, and value: A means-end model and synthesis of evidence. The journal of marketing,52(3) 2-22.

Zhang, Y., Thomas, T., Brussel, M., \& Maarseveen, M. V. (2017). Exploring the impact of built environment factors on the use of public bikes at bike stations: Case study in Zhongshan, China. Journal of Transport Geography, 58, 59-70.

Zhao, J., Deng, W., \& Song, Y. (2014). Ridership and effectiveness of bikesharing: The effects of urban features and system characteristics on daily use and turnover rate of public bikes in China. Transport Policy, 35, 253-264. 


\section{Supporting Agencies:}

1. The Key Fund Project of the Research Center of Regional Public Management Informatization (QGXH18-09).

2. The Key Fund Project of the Research Center of Sichuan County Economy Development (xy2017017).

3. The Chengdu University of Technology Local Undergraduate College Students' Innovation and Entrepreneurship Education Research Base Project (YJ2017-JD002).

\section{Authors:}

1. Yong Liu, PhD student in Management Science and Engineering, Chengdu University of Technology, Chengdu, China. E-mail:523849711@qq.com

ORCID

(iD) 0000-0001-9550-2027

2. Danyu Huang, Master of Industrial Engineering, Chengdu University of Technology, Chengdu, China. E-mail: 550572775 @qq.com

\section{ORCID}

(iD) 0000-0002-9250-450X

3. Meng Wang, Master of Industrial Engineering, Chengdu University of Technology, Chengdu, China. E-mail:346147960@qq.com

ORCID

(iD) 0000-0002-2302-8845

4. Yaru Wang, Master of Industrial Engineering, Chengdu University of Technology, Chengdu, China. E-mail: $1132720939 @ q q . c o m$

ORCID

(D) 0000-0001-8494-1112

\section{Contribution of each author}

\begin{tabular}{|c|c|c|c|c|}
\hline Contribution & Yong Liu & Danyu Huang & Meng Wang & Yaru Wang \\
\hline 1. Definition of research problem & $\sqrt{ }$ & & & \\
\hline 2. Development of hypotheses or research questions (empirical studies) & $\sqrt{ }$ & & & \\
\hline 3. Development of theoretical propositions (theoretical work) & $\sqrt{ }$ & & & \\
\hline 4. Theoretical foundation / Literature review & $\sqrt{ }$ & & & \\
\hline 5. Definition of methodological procedures & $\sqrt{ }$ & $\sqrt{ }$ & $\sqrt{ }$ & \\
\hline 6. Data collection & & $\sqrt{ }$ & $\sqrt{ }$ & $\sqrt{ }$ \\
\hline 7. Statistical analysis & & $\sqrt{ }$ & $\sqrt{ }$ & $\sqrt{ }$ \\
\hline 8. Analysis and interpretation of data & $\sqrt{ }$ & $\sqrt{ }$ & $\sqrt{ }$ & $\sqrt{ }$ \\
\hline 9. Critical revision of the manuscript & $\sqrt{ }$ & $\sqrt{ }$ & & \\
\hline 10. Manuscript writing & $\sqrt{ }$ & & & \\
\hline 11. Other (please specify which) & & & & \\
\hline
\end{tabular}

